Bioética

\section{JURAMENTO OU COMPROMISSO?}

Artigo publicado em The Lancet, Vol 359 de 9 de fevereiro de 2002, traz à tona questão central para nossa reflexão, qual seja o juramento médico. Um expressivo número de entidades médicas norte-americanas e européias considera mais adequado para a contemporaneidade substituir o tradicional juramento hipocrático por um termo de compromissos. Apresentam como princípios fundamentais a primazia do bem-estare autonomia do paciente, assim como a busca de justiça social eliminando as discriminações baseadas em raça, gênero, etnia, religião e posição socioeconômica.

Tratam os autores ainda de responsabilidades profissionais como competência, honestidade com pacientes, confidencialidade, adequada relação médico-paciente, busca de uma melhor qualidade de vida e acesso aos cuidados de saúde, justa distribuição de recursos e habilidade na condução de conflitos de interesses.

\section{Comentário}

Consideramos inteiramente pertinente a abordagem realizada pelos autores. 0 juramento hipocrático, escrito por volta do ano 420 a.C, é um documento precioso da história da humanidade, porém refere-se a práticas realizadas à época e, portanto, incompatíveis com os avanços da hodierna medicina. Em seu enunciado evoca deuses do Olimpo grego como Apolo, Eusculápio, Higéia e Panacéia e considera indigna do exercício profissional práticas cirúrgicas que somente deveriam ser executadas por práticos.

Desde 0 sec. XVIII aprendemos com Immannuel Kant a respeitar a autonomia do ser humano portador de dignidade e, portanto, não podendo ser utilizado como meio por ser um fim em si mesmo. Trata-se de um imperativo categórico do filósofo alemão.

Mais recentemente, Jürgen Habermas, herdeiro da Escola Filosófica de Frankfurt, considera ser impossível fundamentar qualquer procedimento ético sem considerar uma comunidade em permanente comunicação. Ponto-chave na argumentação de Habermas é a passagem do singular para 0 universal. Inconcebível na modernidade, portanto, uma pessoa como emissora da verdade impondo heteronomamente suas decisões sobre outra que as recebe passiva e acriticamente.

Em conclusão, parece mais sensato substituir um juramento revestido de caráter religioso por compromissos que não somente os médicos, mas toda sociedade humana reconheça como autênticos.

\section{José Eduardo de Siqueira}

Referência

"Medical Professionalism in the new millennium: a physicians' charter". Medical Professionalism Project. Lancet 2002; 359:520-2.

\section{Olíciea Oirírgica \\ ENDOSCOPIA COM MAGNIFICAÇÄO: NOVO MÉTODO DE AVALLAÇÃO DO ESÔFAGO DE BARRET}

A endoscopia com magnificação consiste na realização do exame endoscópico com um aparelho que possui o recurso de aumentar a região examinada até 100 vezes, o que permite a observação pormenorizada da mucosa. A princípio utilizada para a colonoscopia, tornou-se popular no Japão, pois possibilita acesso instantâneo e acurado das características microscópicas que distinguem tumores colorretais malignos dos benignos. Stevens et al.'(1994) avaliaram pacientes com esôfago de Barret utilizando endoscópico com magnificação e cromoendoscopia (soluções de lugol e índigo carmin) e concluíram que a técnica permitiu um detalhado exame do esôfago distal, demonstrando claramente um padrão distinto sugestivo de mucosa do tipo intestinal. Guelrud et al. ${ }^{2}(200 \mathrm{I})$ analisaram I29 áreas de 49 pacientes com diagnóstico prévio de segmento curto de Barrett (menor que $3 \mathrm{~cm}$ ). O objetivo era melhorar a detecção das áreas de metaplasia intestinal especializa$\mathrm{da}(\mathrm{MIE})$, que não são vistas na endoscopia convencional. Utilizaram endoscópio com magnificação após instilação de ácido acético a I,5\%. Com a técnica identificaram quatro padrões de mucosa: tipo I pintas arredondadas; II - reticular; III viloso; IV - estriado. O exame histopatológico mostrou que o tipo I não se associa a MIE, enquanto os tipos III e IV estão fortemente relacionados a ela $(87 \%$ e $100 \%)$. Yagi et al. ${ }^{3}(2002)$ detectaram um adenocarcinoma em segmento curto de Barret. Com o aumento de 40 vezes viram duas áreas de aparência amorfa nesse segmento, e o aumento de 80 vezes mostrou capilares anormais. As biópsias confirmaram a suspeita diagnóstica.

\section{Comentário}

A incidência do adenocarcinoma do esôfago distal aumentou no mundo todo, especialmente nos países ocidentais. 0 esôfago de Barrett é um dos principais fatores de risco para o desenvolvimento deste câncer e ocorre não só nos segmentos longos (maiores que $3 \mathrm{~cm}$ ), como também nos curtos. A endoscopia com magnificação, antes utilizada apenas na colonoscopia, desponta como importante método na detecção de áreas suspeitas de metaplasia intestinal ou mesmo de adenocarcinoma do esôfago distal, permitindo a realização de biópsias mais precisas. Todavia o alto custo do equipamento é fator limitante para grande parte das instituições brasileiras não dispor ainda dele.

\section{Mary Ester Yokota \\ Ricardo Borsatto Carlos Alberto Malheiros}

\section{Referências}

I - Stevens PD, Lightdale CJ, Green PH, Siegel LM, Garcia-Carrasquilho RJ, Rotterdam $H$. Combined magnification endoscopy with chromoendoscopy for the evaluation of Barrett's esophagus. Gastrointest Endosc 1994; 40:747-9.

2-GuelrudM, Herrera I, Essenfeld H, Castro J. Enhanced magnification endoscopy: a new technique to identify specialized intestinal metaplasia in Barrett's esophagus. Gastrointest Endosc 2001;53:559-65.

3 - Yagi K, Nakamura A, Sekine A, Tamiya Y, Oyamatsu M. Magnified view of adenocarcinoma in short segment Barret's esophagus treated by endoscopic mucosal resection. Gastrointest Endosc 2002;55: 278-83. 